\title{
Suppressing serum response factor inhibits invasion in cervical cancer cell lines via regulating Egr-1 and epithelial-mesenchymal transition
}

\author{
LIYA MA $^{1 *}$, YING YU ${ }^{2 *}$ and XIAOHUI QU ${ }^{3}$ \\ ${ }^{1}$ Clinical Skills Training Center, Henan University of Chinese Medicine, Zhengzhou, Henan 450046; \\ ${ }^{2}$ Perinatal Care Division, Beijing Obstetrics and Gynecology Hospital, Capital Medical University, \\ Beijing Maternal and Child Health Care Hospital, Beijing 100026; ${ }^{3}$ Obstetrics and Gynecology, \\ Second Affiliated Hospital of Shaanxi University of Chinese Medicine, Xianyang, Shaanxi 712000, P.R. China
}

Received April 19, 2018; Accepted September 27, 2018

DOI: 10.3892/ijmm.2018.3954

\begin{abstract}
Serum response factor (SRF) is a transcription factor that has important roles in tumor progression. However, its role in cervical cancer cell proliferation and invasion remains unclear. The present study revealed that SRF silencing constrained cervical cancer cell proliferation and invasion via controlling early growth response-1 (Egr-1). The results demonstrated that SRF was significantly increased in cervical cancer tissues and cell lines, compared with normal. Suppressing SRF, by using a loss-of-function experiment, constrained cervical cancer cell proliferation, invasion, and epithelial-mesenchymal transition. Furthermore, SRF knockdown significantly downregulated Egr-1 expression in cervical cancer cell lines, and overexpression of Egr-1 reversed the effect of SRF on cell proliferation, invasion, and epithelial-mesenchymal transition. Therefore, SRF may control cell proliferation and invasion by regulating Egr-1 in cervical cancer.
\end{abstract}

\section{Introduction}

Cervical cancer, also known as invasive cervical cancer, is the most common gynecological malignancy, and its incidence

Correspondence to: Dr Xiaohui Qu, Obstetrics and Gynecology, Second Affiliated Hospital of Shaanxi University of Chinese Medicine, 5 Weiyang West Street, Xianyang, Shaanxi 712000, P.R. China

E-mail: xiaohui_quxh@163.com

*Contributed equally

Abbreviations: SRF, serum response factor; EMT, epithelialmesenchymal transition; Egr-1, early growth response-1; RT-qPCR, reverse transcription-quantitative polymerase chain reaction; BrdU, bromodeoxyuridine

Key words: serum response factor, suppression, cervical cancer, early growth response-1, epithelial-mesenchymal transition rate is second only to breast cancer (1). Although screening, surgery, radiotherapy, and other treatments have improved prognoses for early cervical cancer, metastatic and recurrent cases are difficult to eradicate (2). Therefore, elucidating the molecular mechanism of cervical cancer invasion and metastasis has important scientific significance to improve prognosis for patients.

Serum response factor (SRF), a widely expressed transcription factor, belongs to the MADS-box gene family $(3,4)$. SRF regulates cytoskeleton and cell motility, as well as gene expression of immediate early genes, muscle-related genes, and adhesion-related genes (5-8). SRF overexpression promotes tumor cell invasion and metastasis (9). It is associated with downregulation of E-cadherin expression and upregulation of $\mathrm{N}$-cadherin expression in epithelial-mesenchymal transition (EMT) in gastric, peritoneal mesothelial, liver, and prostate cancer cells (10-12). EMT is a crucial process of tumor cell invasion and metastasis, and the loss of the polarity of epithelial cells and migration capacity are important features $(13,14)$. The most important hallmark of EMT is decreased E-cadherin expression. Additionally, $\mathrm{N}$-cadherin is upregulated in EMT and may promote tumor cell migration (15). Currently, the role of SRF in the proliferation and invasion of cervical carcinoma is unclear. The present study aimed to investigate the molecular mechanism of SRF in cervical cancer, and this knowledge could be useful in the future to improve treatment of the disease.

Early growth response-1 (Egr-1), a member of the zinc finger transcription factor family, acts as an early growth response gene $(16,17)$. Egr-1 exerts a variety of biological functions that control synaptic plasticity, wound healing, cell growth, and apoptosis $(18,19)$. The biological function of Egr-1 is associated with the development of human cancer. The absence or increase of abnormally expressed Egr-1 in tumors may be an important cause of tumorigenesis (20). Egr-1 acts as a tumor suppressor in lung cancer and liver cancer, and as a cancer-promoting gene in gastric carcinoma $(19,21,22)$. The role of Egr-1 in EMT of cervical cancer remains unknown.

SRF reportedly activates Egr-1 expression (23). Therefore, it was hypothesized that SRF could affect proliferation and 
invasion in cervical cancer by regulating Egr-1 and EMT. The present study investigated the molecular mechanism of SRF in cervical cancer by measuring SRF expression in cervical cancer cell lines. Cell proliferation and invasion were examined in cervical cancer cell lines following SRF knockdown, and the molecular mechanism underlying the effect of SRF was explored.

\section{Materials and methods}

Cells and tissues. The cervical cancer cell lines ME-180 and HeLa (American Tissue Type Collection, Manassas, VA, USA) were grown in Dulbecco's modified Eagle's medium supplemented with $10 \%$ fetal bovine serum (both from HyClone; GE Healthcare Life Sciences, Logan, UT, USA), 100 U/ml of penicillin, and $100 \mu \mathrm{g} / \mathrm{ml}$ of streptomycin. Human cervical epithelial HCerEpic cells (ScienCell Research Laboratories, Carlsbad, CA, USA) were cultured in cervical epithelial cell medium (ScienCell Research Laboratories). All cells were cultured in an atmosphere of $5 \% \mathrm{CO}_{2}$ at $37^{\circ} \mathrm{C}$.

Cervical tumor samples $(n=10)$ were collected from cervical cancerous area of patients in the Henan University of Chinese Medicine (Zhengzhou, China) undergoing hysterectomies without radiotherapy or chemotherapy. Normal tissues $(n=10)$ were collected from patients undergoing surgery for myoma or adenomyoma. Normal tissue samples were nonmalignant and negative for human papilloma virus and ThinPrep cytological tests. All patients in the present study were 40-50 years old. Samples were collected under a protocol approved by the Institutional Review Board of the Henan University of Chinese Medicine (Zhengzhou, China) between December 2016 and August 2017. Informed consent was obtained from the patients.

Reverse transcription-quantitative polymerase chain reaction (RT-qPCR) assay. Total RNA from cells or tissues was extracted by using TRIzol (Takara Biotechnology Co., Ltd., Dalian, China) and $5 \mu \mathrm{g}$ RNA was synthesized into cDNA with a Revert Aid First Strand cDNA Synthesis kit (Thermo Fisher Scientific, Inc., Waltham, MA, USA) according to the manufacturer's protocol.

The qPCR reaction $(20 \mu \mathrm{l})$ contained $10 \mu \mathrm{l}$ SYBR Premix Ex Taq II (Takara Biotechnology Co., Ltd.) as the enzyme mixture. The reaction program was as follows: $94^{\circ} \mathrm{C}$ for $30 \mathrm{sec}, 40 \mathrm{cycles}$ at $94^{\circ} \mathrm{C}$ for $10 \mathrm{sec}, 60^{\circ} \mathrm{C}$ for $30 \mathrm{sec}$, and $72^{\circ} \mathrm{C}$ for $30 \mathrm{sec}$. Primers were as follows: SRF, forward, 5'-TTC AAGGTAGAGAAGACTGGTTT-3' and reverse, 5'-CTGACC CCCATTCCTGTGTC-3'; GAPDH, forward, 5'-GGAAGA TGGTGATGGGATT-3' and reverse, 5'-GGATTTGGTCGT ATT GGG-3'; and Egr-1, forward, 5'-AGCCCTACGAGCACC TGA C-3' and reverse, 5'-GGTTTGGCTGGGGTAACTG-3'. The relative levels of gene expression were estimated using the $2^{-\Delta \Delta \mathrm{Cq}}$ method (24).

Western blot analysis. Protein was extracted with RIPA lysis buffer and was quantified with a BCA kit (both from Beyotime Institute of Biotechnology, Haimen, China). Total protein samples $(25 \mu \mathrm{g})$ were separated by $12 \%$ SDS-PAGE and transferred onto polyvinylidene fluoride membranes (Bio-Rad Laboratories, Inc., Hercules, CA, USA) by electrophoretic transfer. The membrane was then incubated with
$5 \%$ skim milk for $2 \mathrm{~h}$, followed by incubation overnight at $4^{\circ} \mathrm{C}$ with the following primary antibodies (Cell Signaling Technology, Inc., Danvers, MA, USA): anti-SRF (1:500; cat. no. 5147), anti-Egr-1 (1:500; cat. no. 4154), anti-E-cadherin (1:800; cat. no. 3195$)$, anti-N-cadherin (1:800; cat. no. 13116), and anti-GAPDH (1:500; cat. no. 5174). Next, the membrane was incubated with secondary antibody (1:800; cat. no. 7074, Cell Signaling Technology, Inc.) diluted in the blocking buffer. Finally, the protein was detected using enhanced chemiluminescence. GAPDH was used as the protein loading control. Optical density of the bands was measured with the BandScan imaging analysis system (Glyko Inc., Hayward, CA, USA).

Construction of the recombinantplasmids and cell transfection. The full-length cDNA of Egr-1 (accession no., NM_001964) was amplified by RT-PCR and incubated with EcoRI and BamHI enzymes. Subsequently, pcDNA.3.1/myc-His(-) Avector (Invitrogen; Thermo Fisher Scientific, Inc.) was also incubated with those two enzymes and the Egr-1 fragment was inserted at the EcoRI and BamHI restriction sites. The recombinant plasmid was then amplified in DH5 Escherichia coli-competent cells (Takara Biotechnology Co.,Ltd.), followed by extraction using a Takara MiniBEST Plasmid Purification kit version 4.0. Finally, the plasmid was sequenced, and the correct ones were selected as pcDNA.3.1-Egr-1.

Cell transfection was as follows: ME-180 and HeLa cells were separately cultured in 96-well plates under a humid atmosphere with $5 \% \mathrm{CO}_{2}$ at $37^{\circ} \mathrm{C}$. The transfection program was based on TurboFect (Thermo Fisher Scientific, Inc.) and followed the manufacturer protocol. Cell transfection was conducted when cells are at $\sim 80 \%$ confluency. The pcDNA.3.1-Egr-1 $(0.3 \mu \mathrm{g})$, pcDNA.3.1 $(0.3 \mu \mathrm{g})$, SRF small interfering (si) RNA (5'-AAC CACCCGCCACTCTTCCT-3', $(0.3 \mu \mathrm{g})$, and non-specific siRNA (5'-ATTCACCGACTATCCAACAT-3', $0.3 \mu \mathrm{g}$ ) were transfected separately with $2 \mu \mathrm{l}$ of TurboFect. The cells were then cultured in $5 \% \mathrm{CO}_{2}$ at $37^{\circ} \mathrm{C}$ for $24 \mathrm{~h}$. Transfection efficiency was measured by RT-qPCR and western blot assays.

Cell viability assay. MTT was used to detect cell viability. Cells were cultured in 96 -well plates at $37^{\circ} \mathrm{C}$ for $24 \mathrm{~h}$. The culture medium was then changed to PBS containing MTT (20 $\mu \mathrm{l} /$ well) and incubated for another $4.5 \mathrm{~h}$ at $37^{\circ} \mathrm{C}$. Afterwards, dimethyl sulfoxide $(150 \mu \mathrm{l} /$ well $)$ was added to dissolve the formazan. Results were measured using a microplate reader (Thermo Fisher Scientific, Inc.) at $490 \mathrm{~nm}$.

Bromodeoxyuridine (BrdU) assay. Cell proliferation was assessed using a BrdU kit (EMD Biosciences, Inc., Darmstadt, Germany) according to the specification sheets. Briefly, cells were cultured in a 96-well plate followed by $1 \mathrm{~h}$ of incubation with $10 \mu \mathrm{l}$ of BrdU solution per well. After discarding the culture medium, a denaturing solution $(180 \mu \mathrm{l})$ was added and incubated for $35 \mathrm{~min}$. Cells were then incubated with an anti-BrdU antibody conjugated with peroxidase for $30 \mathrm{~min}$. The results were measured at $450 \mathrm{~nm}$ using a SpectroFluor Plus multi-well plate reader (Tecan Group Ltd., Mannedorf, Switzerland).

Cell invasion.Cell invasion ability wastested using Bio-Coat cell migration chambers (Corning Incorporated, Toledo, NY, USA) 

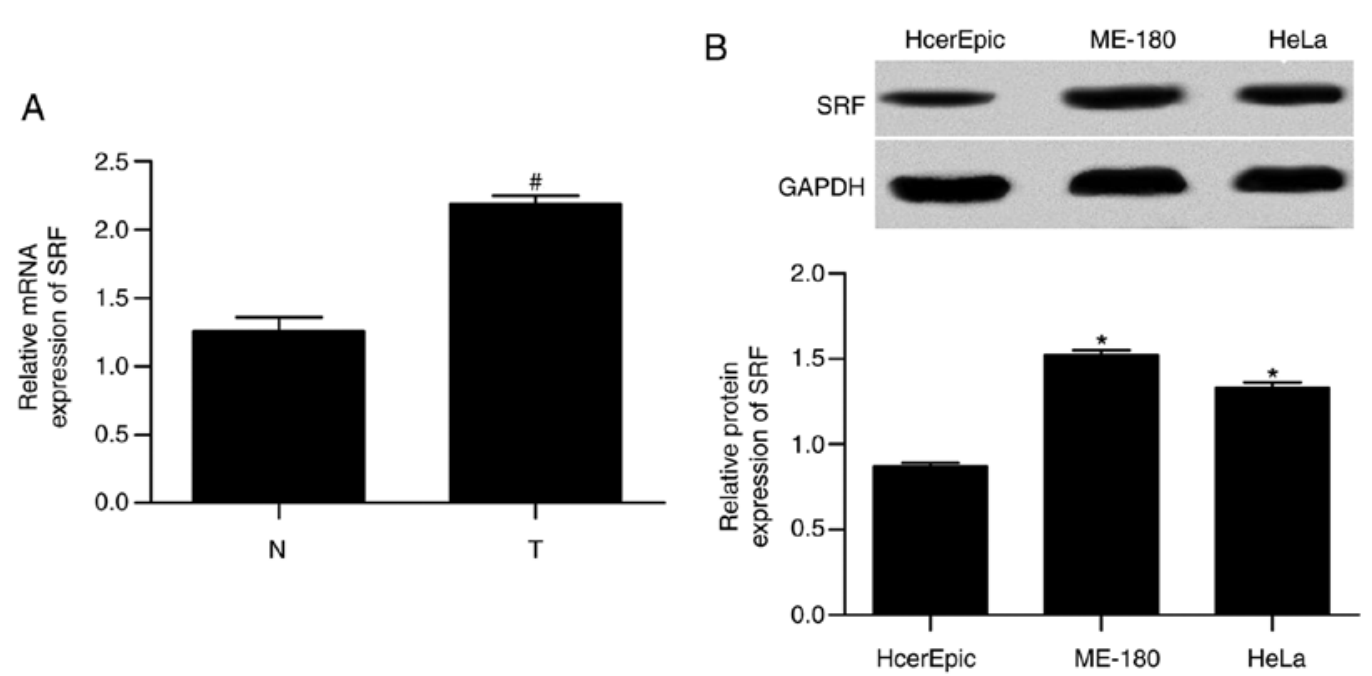

Figure 1. Expression of SRF in cervical cancer tissues and cell lines. (A) Relative SRF mRNA levels were measured in cervical cancer tissues and normal tissues from patients $(\mathrm{n}=10) .{ }^{\#} \mathrm{P}<0.05$ vs. $\mathrm{N}$ group. (B) SRF protein expression levels were measured in cervical cancer cell lines and in the normal cervical epithelial cell line HCerEpic, by western blotting $(\mathrm{n}=3)$. GAPDH was used as the internal control. " $\mathrm{P}<0.05$ vs. HCerEpic group. SRF, serum response factor; $\mathrm{N}$, normal; T, tumor.

coated with Matrigel (BD Biosciences, Franklin Lakes, NJ, USA). Transfected cells ( $1 \times 10^{5}$ cells) were suspended in $200 \mu 1$ of serum-free medium and then plated in the upper chamber. Complete medium $(300 \mu \mathrm{l})$ was added to the lower chamber and incubated at $37^{\circ} \mathrm{C}$ for $48 \mathrm{~h}$. Non-invading cells were gently removed with a cotton swab from the upper chambers. Invaded cells were fixed, stained, and observed using a light microscope. Ten visual fields in each membrane were randomly selected for cell number counting.

Statistical analysis. Statistical analyses were processed with SPSS version 22.0 software (IBM Corporation, Armonk, NY, USA). Differences between multiple groups were evaluated with one-way analysis of variance followed by a Bonferroni test. Differences between normal and tumor samples were evaluated with the Mann-Whitney's U test. Data are expressed as the mean \pm standard deviation. $\mathrm{P}<0.05$ was considered to indicate a statistically significant difference.

\section{Results}

SRF is upregulated in cervical cancer cell lines and tissues. First, the mRNA expression levels in tissues and the protein expression levels in cell lines were measured for SRF by RT-qPCR and western blotting, respectively. The results demonstrated that mRNA expression (Fig. 1A) in tissues and protein expression (Fig. 1B) in cell lines were significantly increased in cervical cancer compared with normal, implying an important role of SRF in cervical cancer.

SRF silencing suppresses proliferation in cervical cancer cells. To investigate the role of SRF in cervical cancer cell proliferation, MTT and BrdU assays were used to detect proliferation in th cervical cancer cell lines ME-180 and HeLa, following SRF knockdown. First, SRF siRNA was transfected into ME-180 and HeLa cells in order to knockdown SRF expression. The data demonstrated that both the mRNA (Fig. 2A) and protein (Fig. 2B) levels of SRF were successfully decreased by $>50 \%$. Next, ME-180 and HeLa cell proliferation was measured. In the MTT assay (Fig. 2C), cell proliferation was significantly decreased in the cells following SRF knockdown, compared with the control cells. Similarly, in the BrdU assay (Fig. 2D), cell proliferation also appeared to be markedly downregulated following SRF knockdown.

SRF silencing suppresses invasion in cervical cancer cells. Cell invasion of ME-180 and HeLa cells following SRF knockdown by siRNA was measured by Transwell assays. Expression of the established EMT markers E-cadherin and $\mathrm{N}$-cadherin was also investigated by western blotting. As presented in Fig. 3A, the results from the Transwell assays revealed that cell invasion was significantly decreased following SRF knockdown in ME-180 and HeLa cells. The western blotting results demonstrated that E-cadherin protein expression was upregulated 2-fold, while $\mathrm{N}$-cadherin was markedly downregulated in ME-180 and HeLa cells following SRF knockdown (Fig. 3B).

SRF silencing downregulates Egr-1 expression. Egr-1 has been reported to be regulated by SRF and it affects EMT progression. Thus, it was speculated that SRF may control Egr-1 expression in cervical cancer cell lines. The mRNA (Fig. 4A) and protein (Fig. 4B) expression levels of Egr-1 were detected in ME-180 and HeLa cells following SRF knockdown. Egr-1 expression was significantly decreased in cervical cancer cell lines following SRF silencing.

SRF silencing controls cervical cancer cell line proliferation and invasion by regulating Egr-1. To explore the molecular mechanism of SRF in regulating cervical cancer cell proliferation and invasion, a gain-of-function experiment was performed for Egr-1 in SRF-knockdown ME-180 and HeLa cell lines. When the SRF-knockdown cells were transfected with an Egr-1-overexpressing plasmid, Egr-1 was upregulated by 3 -fold compared with cells transfected with an empty plasmid, suggesting that overexpression was successful (Fig. 5A). Next, the effect of Egr-1 overexpression 
A

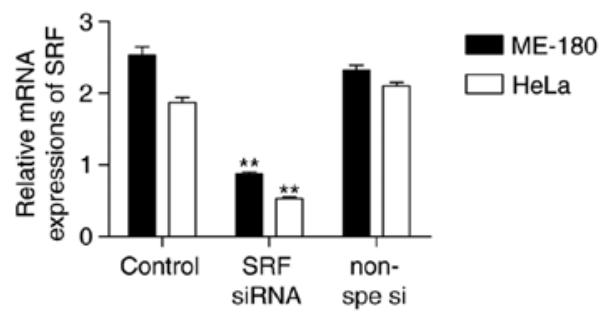

C

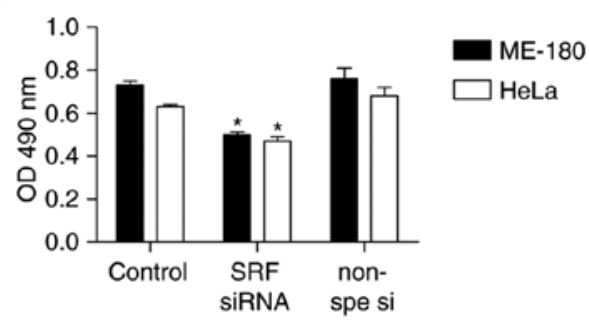

B
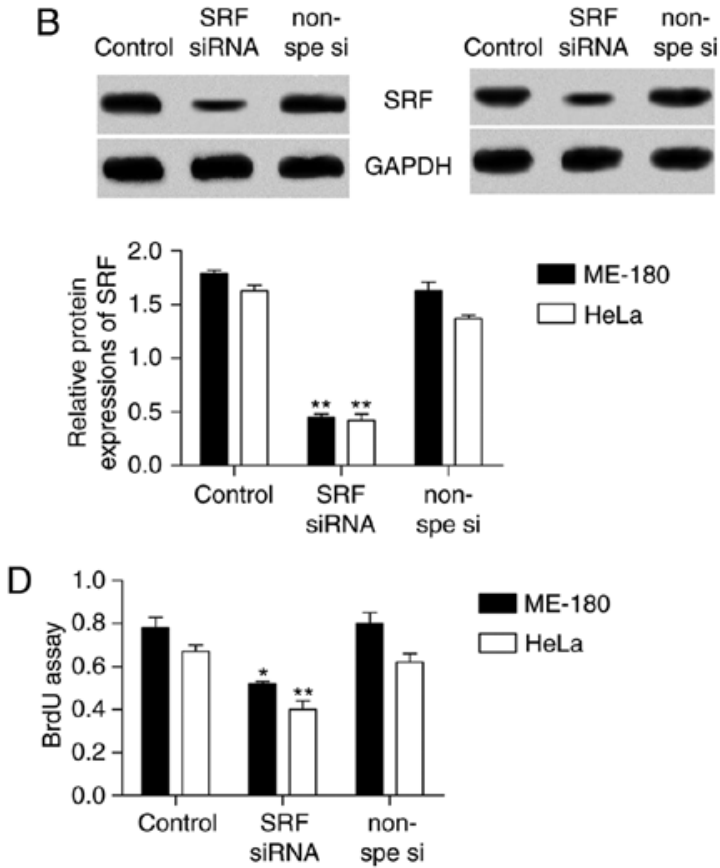

Figure 2. Effect of SRF silencing on cervical cancer cell proliferation. (A) Relative mRNA levels and (B) protein levels of SRF in cervical cancer cell lines following transfection with SRF siRNA or non-specific siRNA. (C) Proliferation of cervical cancer cells with SRF knockdown was measured by MTT and (D) BrdU assays. " $\mathrm{P}<0.05$ and ${ }^{* *} \mathrm{P}<0.01$ vs. the non-specific si group ( $\left.\mathrm{n}=3\right)$. SRF, serum response factor; si, small interfering; BrdU, bromodeoxyuridine.
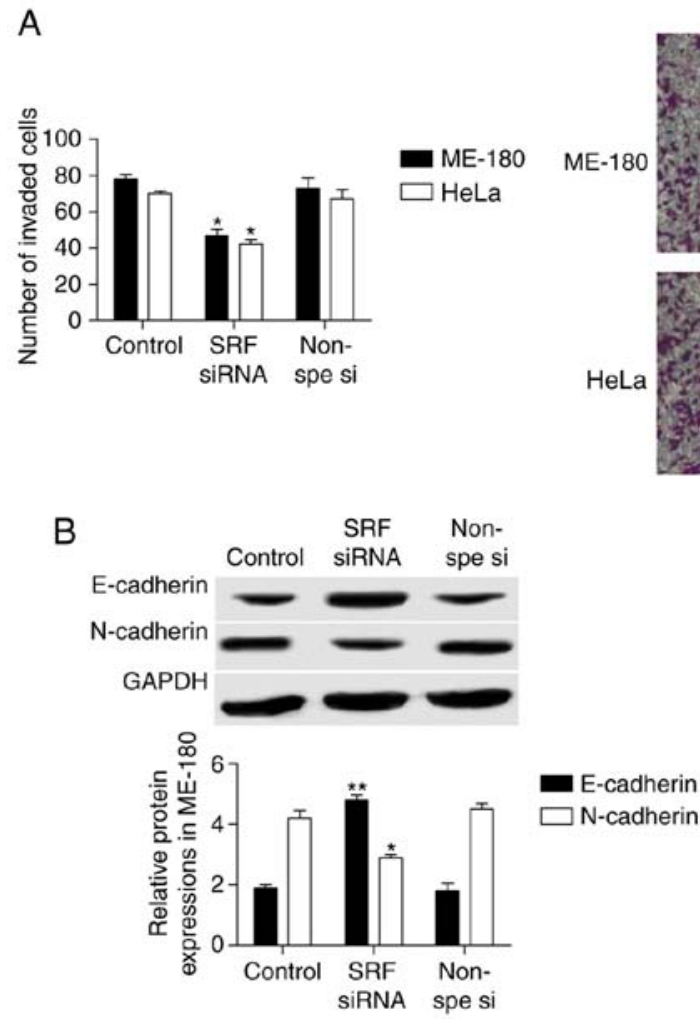

Control

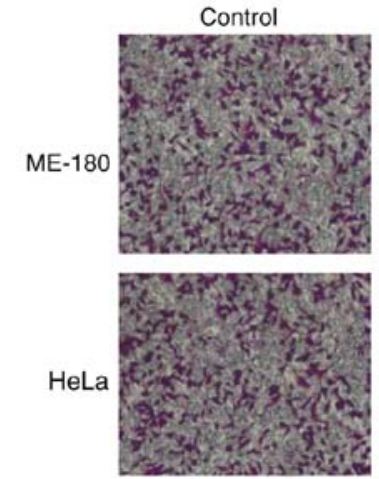

SRF siRNA

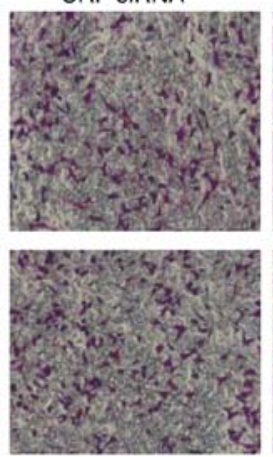

Non-spe si

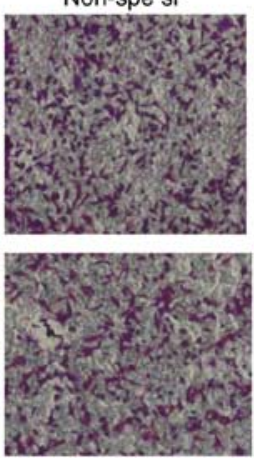

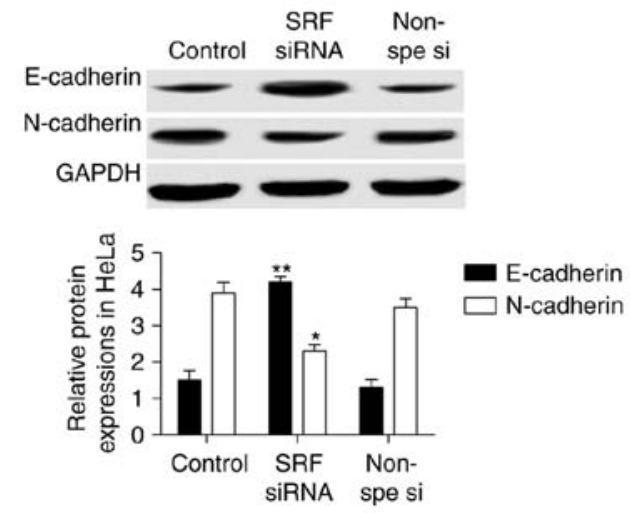

Figure 3. Effects of SRF silencing on invasion and EMT in cervical cancer cells. (A) Invasion was assessed by Transwell invasion assays in cervical cancer cell lines. (B) Protein expression levels of established EMT markers were assessed by western blot analysis. ${ }^{*} \mathrm{P}<0.05$ and ${ }^{* *} \mathrm{P}<0.01$ vs. the non-specific si group $(n=3)$. SRF, serum response factor; EMT, epithelial-mesenchymal transition; si, small interfering.

was investigated on cell proliferation and invasion. The results demonstrated that Egr-1 overexpression in ME-180 and HeLa cells reversed the inhibitory effect of SRF knockdown on proliferation (by MTT assay; Fig. 5B) and on invasion (by
Transwell assay; Fig. 5C). Furthermore, E-cadherin protein expression was significantly decreased, and $\mathrm{N}$-cadherin increased (Fig. 5A). Therefore, SRF controlled cervical cancer cell proliferation and invasion through Egr-1. 

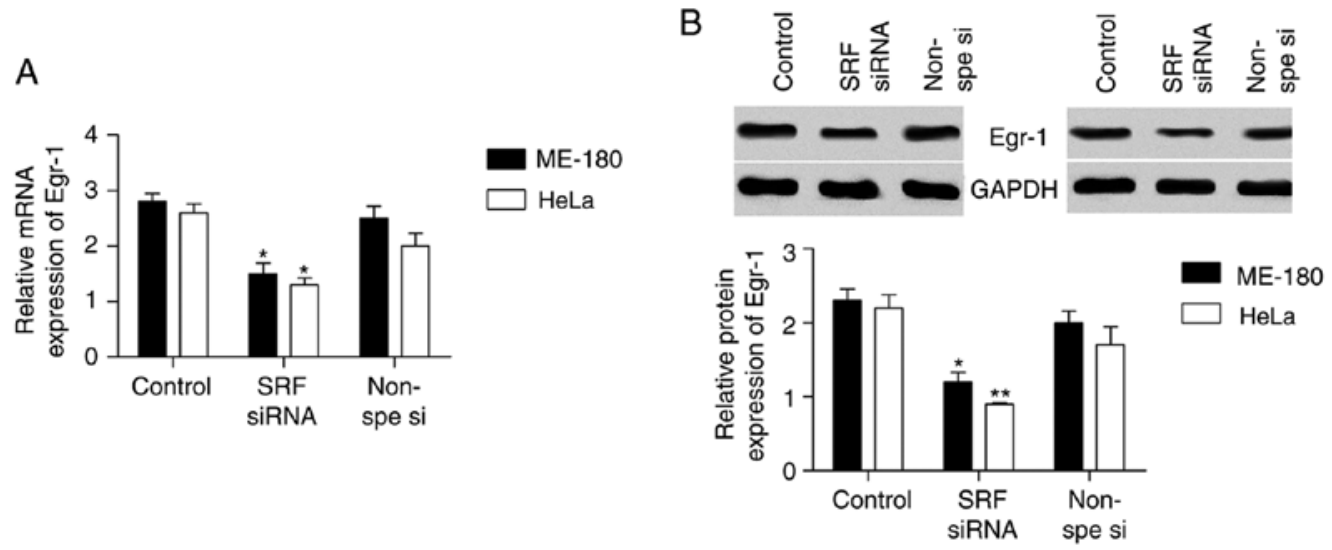

Figure 4. Egr-1 expression following SRF silencing. (A) The relative mRNA levels and (B) protein levels of Egr-1 were measured in cervical cancer cell lines following SRF silencing by siRNA. " $\mathrm{P}<0.05$ and ${ }^{* *} \mathrm{P}<0.01$ vs. the non-specific si group $(\mathrm{n}=3)$. Egr-1, early growth response-1; SRF, serum response factor; si, small interfering.
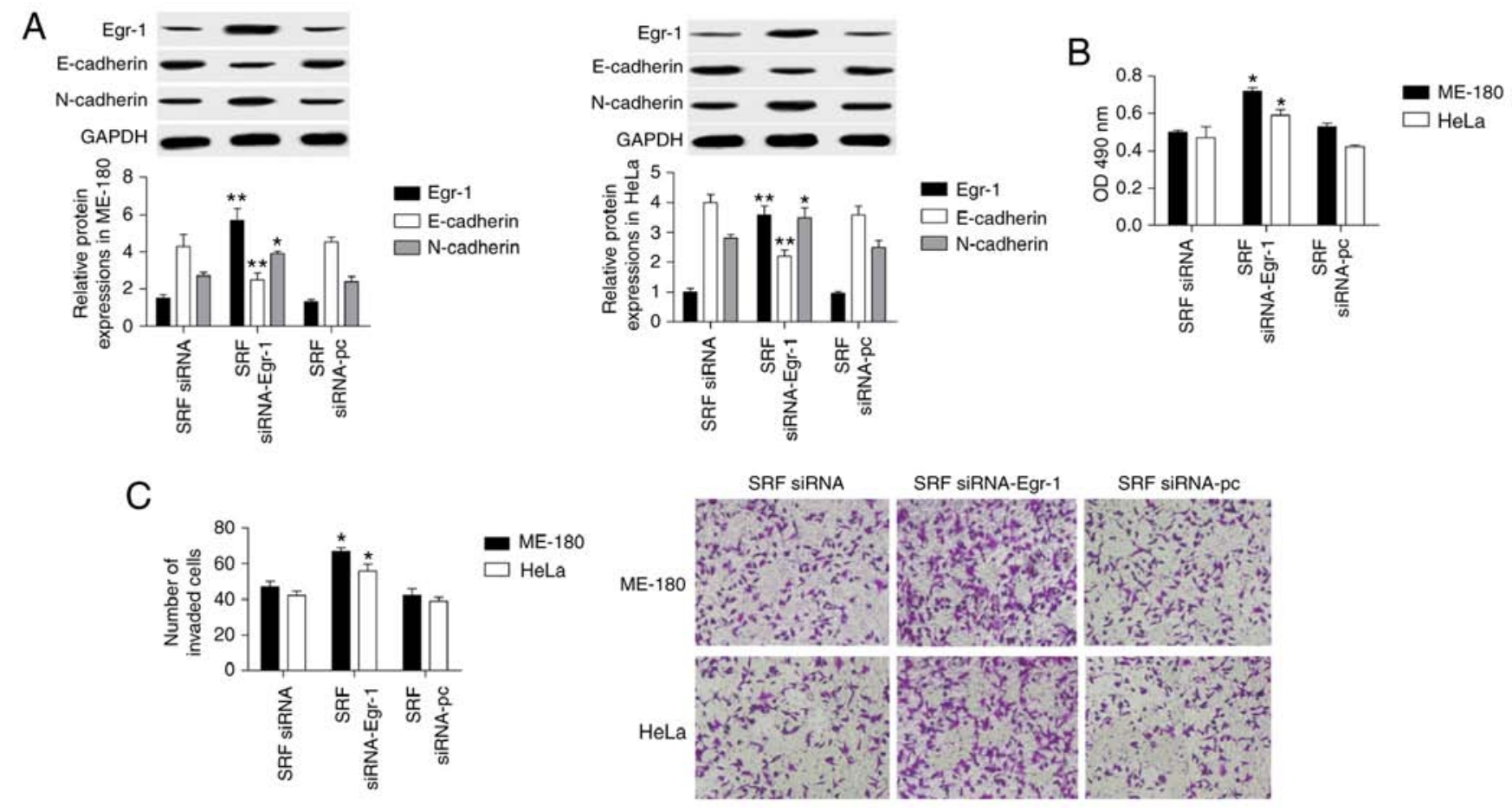

Figure 5. Effect of Egr-1 overexpression on cell proliferation and invasion following SRF silencing. SRF knockdown cervical cancer cells were transfected with either an Egr-1 overexpressing vector or empty vector control. (A) The protein expression levels of Egr-1, E-cadherin and N-cadherin were detected by western blotting. (B) Proliferation was measured by MTT assay. (C) Invasion was measured by Transwell invasion assay. ${ }^{*} \mathrm{P}<0.05$ and ${ }^{* *} \mathrm{P}<0.01$ vs. the SRF siRNA-pc group ( $\mathrm{n}=3$ ). Egr-1, early growth response-1; SRF, serum response factor; si, small interfering; pc, empty plasmid control.

\section{Discussion}

According to the World Health Organization, 500,000 new cases of cervical cancer occur worldwide each year, $\sim 80 \%$ in developing countries (25). Cervical cancer rates continue to rise and affect younger women (26). SRF is closely associated with cancer metastasis. SRF expression is elevated in prostate and gastric cancers (27). Zhao et al (10) reported that SRF modulates EMT and promotes metastasis in human gastric cancer. Wang et al (28) reported that SRF regulates non-small-cell lung cancer invasion and proliferation via the miR29b/matrix metallopeptidase 2 axis. SRF siRNA has been indicated to reduce the invasion potential of prostate cancer cells in vitro (12).
SRF is an important transcription factor that regulates EMT (29). EMT is a process of cytoskeletal rearrangement that increases cell migration and invasion abilities (30). Studies generally agree that EMT is associated with embryonic development, tissue regeneration, and cancer metastasis $(31,32)$. During tumorigenesis, EMT is characterized by downregulation of E-cadherin, which causes differentiated epithelial tumor cells to become tumorigenic cells with migration and invasion abilities (33). Upregulation of N-cadherin promotes EMT (34). He et al (35) demonstrated that SRF promotes EMT in human peritoneal mesothelial cells. SRF also provokes EMT in renal tubular epithelial cells of diabetic nephropathy (36), and it induces EMT 
in hepatocellular carcinoma, prostate cancer, and gastric cancer (37). Therefore, SRF has a significant role in EMT and cancer metastasis. Nevertheless, its role in cervical cancer remains unclear. In the present study, it was demonstrated that SRF expression in cervical cancer tissues and cell lines was highly increased compared with normal. A loss-of-function experiment was performed by transfecting SRF siRNA in cervical cancer cell lines, and SRF silencing significantly decreased $\mathrm{N}$-cadherin and increased E-cadherin expression in cervical cancer cell lines. In addition, cell proliferation and invasion were suppressed following SRF silencing.

Silverman and Collins (23) demonstrated that Egr-1 gene transcription could be activated by SRF. Egr-1 gene expression can be regulated by a variety of extracellular signals, subsequently modulating cell proliferation and invasion (38). Egr-1 also directly affects cell proliferation in astrocytes, glioma cells, and mesangial cells (39-41). Additionally, it is closely related to EMT and cell invasion in nasopharyngeal cancer, human ovarian cancer, colon cancer, and thyroid cancer cells $(20,42,43)$. Egr-1 serves different roles in different cancer cells. Previous studies have demonstrated that Egr-1 decreases the malignancy of human non-small-cell lung carcinoma by regulating type I intermediate filament chain keratin 18 expression, whereas Egr-1 promotes growth in prostate cancer cells $(44,45)$.

The effect of Egr-1 on cervical cancer is unclear. The present study demonstrated that Egr-1 decreased when SRF was silenced in cervical cancer cell lines. Notably, Egr-1 overexpression abolished the effect of SRF silencing on cell proliferation, invasion, and E-cadherin and N-cadherin expressions in cervical cancer cells. Therefore, SRF inhibition may control cervical cancer metastasis by modulating Egr-1 expression. The data in the present study demonstrated that SRF was highly expressed in clinical cervical cancer tissues and cell lines compared with normal. SRF knockdown restrained Egr-1 expression, resulting in repression of proliferation, invasion and $\mathrm{N}$-cadherin expression and induction of E-cadherin expression. Thus, the current study provides a novel insight into the molecular mechanism of SRF in cervical cancer and provides a potential target for treatment. Because the present study was performed mostly in vitro, further studies with additional tissue samples or in vivo will be required in the future to fully characterize the role of SRF in human cervical cancer.

\section{Acknowledgements}

Not applicable.

\section{Funding}

No funding was received.

\section{Availability of data and materials}

The analyzed data sets generated during the study are available from the corresponding author on reasonable request.

\section{Authors' contributions}

LM and YY designed and prepared the experiments. LM and YY performed the experiments. LM, XQ and YY contributed reagents/materials/analysis tools. LM and YY wrote the manuscript. XQ modified and revised the manuscript. All authors read and approved the final manuscript.

\section{Ethics approval and consent to participate}

Patient samples were collected under a protocol approved by the Institutional Review Board of the Henan University of Chinese Medicine (Zhengzhou, China), and informed consent was obtained from all patients.

\section{Patient consent for publication}

Not applicable.

\section{Competing interests}

The authors declare that they have no competing interests.

\section{References}

1. Arnold M, Liu L, Kenter GG, Creutzberg CL, Coebergh JW and Soerjomataram I: Second primary cancers in survivors of cervical cancer in the netherlands: Implications for prevention and surveillance. Radiother Oncol 111: 374-381, 2014.

2. Milosevic MF, Pintilie M, Hedley DW, Bristow RG, Wouters BG, Oza AM, Laframboise S, Hill RP and Fyles AW: High tumor interstitial fluid pressure identifies cervical cancer patients with improved survival from radiotherapy plus cisplatin versus radiotherapy alone. Int J Cancer 135: 1692-1699, 2014

3. Profantova B, Coic YM, Profant V, Štěpánek J, Kopecký V Jr, Turpin PY, Alpert B and Zentz C: Organization of the MADS box from human SRF revealed by tyrosine perturbation. J Phys Chem B 119: 1793-1801, 2015.

4. Yu LH, Wu J, Zhang ZS, Miao ZQ, Zhao PX, Wang Z and Xiang CB: Arabidopsis MADS-box transcription factor AGL21 acts as environmental surveillance of seed germination by regulating ABI5 expression. Mol Plant 10: 834-845, 2017.

5. Stern $\mathrm{S}$ and Knoll B: CNS axon regeneration inhibitors stimulate an immediate early gene response via MAP kinase-SRF signaling. Mol Brain 7: 86, 2014.

6. Ji H, Atchison L, Chen Z, Chakraborty S, Jung Y, Truskey GA, Christoforou $\mathrm{N}$ and Leong KW: Transdifferentiation of human endothelial progenitors into smooth muscle cells. Biomaterials 85 : 180-194, 2016.

7. Manning CS, Hooper S and Sahai EA: Intravital imaging of SRF and Notch signalling identifies a key role for EZH2 in invasive melanoma cells. Oncogene 34: 4320-4332, 2015.

8. Sharili AS, Kenny FN, Vartiainen MK and Connelly JT: Nuclear actin modulates cell motility via transcriptional regulation of adhesive and cytoskeletal genes. Sci Rep 6: 33893, 2016.

9. Urbini M, Astolfi A, Indio V, Tarantino G, Serravalle S, Saponara M, Nannini M, Gronchi A, Fiore M, Maestro R, et al: Identification of SRF-E2F1 fusion transcript in EWSR-negative myoepithelioma of the soft tissue. Oncotarget 8: 60036-60045, 2017.

10. Zhao X, He L, Li T, Lu Y, Miao Y, Liang S, Guo H, Bai M, Xie H, Luo G, et al: SRF expedites metastasis and modulates the epithelial to mesenchymal transition by regulating miR-199a-5p expression in human gastric cancer. Cell Death Differ 21: 1900-1913, 2014.

11. Li YJ, Dong M, Kong FM and Zhou JP: Folate-decorated anticancer drug and magnetic nanoparticles encapsulated polymeric carrier for liver cancer therapeutics. Int J Pharm 489: 83-90, 2015.

12. Evans JC, McCarthy J, Torres-Fuentes C, Cryan JF, Ogier J, Darcy R, Watson RW and O'Driscoll CM: Cyclodextrin mediated delivery of NF-kappaB and SRF siRNA reduces the invasion potential of prostate cancer cells in vitro. Gene Ther 22: 802-810, 2015.

13. Burute M, Prioux M, Blin G, Truchet S, Letort G, Tseng Q, Bessy T, Lowell S, Young J, Filhol O and Théry M: Polarity reversal by centrosome repositioning primes cell scattering during epithelial-to-mesenchymal transition. Dev Cell 40: 168-184, 2017. 
14. Bhattacharya R, Mitra T, Ray Chaudhuri S and Roy SS Mesenchymal splice isoform of CD44 (CD44s) promotes EMT/invasion and imparts stem-like properties to ovarian cancer cells. J Cell Biochem 119: 3373-3383, 2018.

15. Labernadie A, Kato T, Brugues A, Serra-Picamal X, Derzsi S, Arwert E, Weston A, González-Tarragó V, Elosegui-Artola A, Albertazzi L, et al: A mechanically active heterotypic E-cadherin/ $\mathrm{N}$-cadherin adhesion enables fibroblasts to drive cancer cell invasion. Nat Cell Biol 19: 224-237, 2017.

16. Li Y, McRobb LS and Khachigian LM: MicroRNA miR-191 targets the zinc finger transcription factor Egr-1 and suppresses intimal thickening after carotid injury. Int J Cardiol 212: 299-302, 2016.

17. Khachigian LM: Early growth response-1 in the pathogenesis of cardiovascular disease. J Mol Med (Berl) 94: 747-753, 2016.

18. Groger N, Bock J, Goehler D, Blume N, Lisson N, Poeggel G and Braun K: Stress in utero alters neonatal stress-induced regulation of the synaptic plasticity proteins arc and egr1 in a sex-specific manner. Brain Struct Funct 221: 679-685, 2016.

19. Ryu JW, Choe SS, Ryu SH, Park EY, Lee BW, Kim TK, Ha CH and Lee SW: Paradoxical induction of growth arrest and apoptosis by EGF via the up-regulation of PTEN by activating Redox factor-1/Egr-1 in human lung cancer cells. Oncotarget 8 : 4181-4195, 2017

20. Cheng JC, Chang HM and Leung PC: Egr-1 mediates epidermal growth factor-induced downregulation of E-cadherin expression via Slug in human ovarian cancer cells. Oncogene 32: 1041-1049, 2013.

21. Peng WX, Wan YY, Gong AH, Ge L, Jin J, Xu M and Wu CY: Egr-1 regulates irradiation-induced autophagy through atg4B to promote radioresistance in hepatocellular carcinoma cells. Oncogenesis 6: e292, 2017.

22. Park SY, Kim JY, Lee SM, Chung JO, Lee KH, Jun CH, Park CH, Kim HS, Choi SK, Rew JS, et al: Expression of early growth response gene-1 in precancerous lesions of gastric cancer. Oncol Lett 12: 2710-2715, 2016

23. Silverman ES and Collins T: Pathways of Egr-1-mediated gene transcription in vascular biology. Am J Pathol 154: 665-670, 1999.

24. Livak KJ and Schmittgen TD: Analysis of relative gene expression data using real-time quantitative PCR and the 2(-Delta Delta C(T)) method. Methods 25: 402-408, 2001.

25. Cuzick J, Arbyn M, Sankaranarayanan R, Tsu V, Ronco G, Mayrand MH, Dillner J and Meijer CJ: Overview of human papillomavirus-based and other novel options for cervical cancer screening in developed and developing countries. Vaccine 10 (Suppl 26): K29-K41, 2008.

26. Fidler MM, Gupta S, Soerjomataram I, Ferlay J, SteliarovaFoucher E and Bray F: Cancer incidence and mortality among young adults aged 20-39 years worldwide in 2012: A population-based study. Lancet Oncol 18: 1579-1589, 2017

27. Qiao J, Liu Z, Yang C, Gu L and Deng D: SRF promotes gastric cancer metastasis through stromal fibroblasts in an SDF1-CXCR4-dependent manner. Oncotarget 7: 46088-46099, 2016.

28. Wang HY, Tu YS, Long J, Zhang HQ, Qi CL, Xie XB, Li SH and Zhang YJ: SRF-miR29b-MMP2 axis inhibits NSCLC invasion and metastasis. Int J Oncol 47: 641-649, 2015.

29. Schwartz B, Marks M, Wittler L, Werber M, Währisch S, Nordheim A, Herrmann BG and Grote P: SRF is essential for mesodermal cell migration during elongation of the embryonic body axis. Mech Dev 133: 23-35, 2014.
30. Wang H, Tao L, Jin F, Gu H, Dai X, Ni T, Feng J, Ding Y, Xiao W, Qian Y and Liu Y: Cofilin 1 induces the epithelial-mesenchymal transition of gastric cancer cells by promoting cytoskeletal rearrangement. Oncotarget 8: 39131-39142, 2017.

31. Nieto MA: Context-specific roles of EMT programmes in cancer cell dissemination. Nat Cell Biol 19: 416-418, 2017.

32. Pesic M and Greten FR: Inflammation and cancer: Tissue regeneration gone awry. Curr Opin Cell Biol 43: 55-61, 2016.

33. Rogers CD, Saxena A and Bronner ME: Sipl mediates an E-cadherin-to-N-cadherin switch during cranial neural crest EMT. J Cell Biol 203: 835-847, 2013.

34. Chen L, Munoz-Antonia T and Cress WD: Trim 28 contributes to EMT via regulation of E-cadherin and $\mathrm{N}$-cadherin in lung cancer cell lines. PLoS One 9: e101040, 2014.

35. He L, Lou W, Ji L, Liang W, Zhou M, Xu G, Zhao L, Huang C, Li R, Wang H, et al: Serum response factor accelerates the high glucose-induced epithelial-to-mesenchymal transition (EMT) via snail signaling in human peritoneal mesothelial cells. PLoS One 9: e108593, 2014

36. Zhao L, Chi L, Zhao J, Wang X, Chen Z, Meng L, Liu G, Guan G and Wang F: Serum response factor provokes epithelial-mesenchymal transition in renal tubular epithelial cells of diabetic nephropathy. Physiol Genomics 48: 580-588, 2016.

37. Zhao L, Zhao J, Wang X, Chen Z, Peng K, Lu X, Meng L, Liu G, Guan G and Wang F: Serum response factor induces endothelial-mesenchymal transition in glomerular endothelial cells to aggravate proteinuria in diabetic nephropathy. Physiol Genomics 48: 711-718, 2016.

38. Sun T, Tian H, Feng YG, Zhu YQ and Zhang WQ: Egr-1 promotes cell proliferation and invasion by increasing beta-catenin expression in gastric cancer. Dig Dis Sci 58: 423-430, 2013.

39. Mayer SI, Rossler OG, Endo T, Charnay P and Thiel G: Epidermal-growth-factor-induced proliferation of astrocytes requires Egr transcription factors. J Cell Sci 122: 3340-3350, 2009.

40. Kaufmann $\mathrm{K}$ and Thiel G: Epidermal growth factor and platelet-derived growth factor induce expression of Egr-1, a zinc finger transcription factor, in human malignant glioma cells. J Neurol Sci 189: 83-91, 2001.

41. Li Y, Hu F, Xue M, Jia YJ, Zheng ZJ, Wang L, Guan MP and Xue YM: Klotho down-regulates Egr-1 by inhibiting TGF- $\beta 1 /$ Smad3 signaling in high glucose treated human mesangial cells. Biochem Biophys Res Commun 487: 216-222, 2017.

42. Lee BS, Kang S, Kim KA, Song YJ, Cheong KH, Cha HY and Kim CH: Met degradation by SAIT301, a met monoclonal antibody, reduces the invasion and migration of nasopharyngeal cancer cells via inhibition of EGR-1 expression. Cell Death Dis 5: e1159, 2014.

43. Kim J, Kang HS, Lee YJ, Lee HJ, Yun J, Shin JH, Lee CW, Kwon BM and Hong SH: EGR1-dependent PTEN upregulation by 2-benzoyloxycinnamaldehyde attenuates cell invasion and EMT in colon cancer. Cancer Lett 349: 35-44, 2014.

44. Baron V, De Gregorio G, Krones-Herzig A, Virolle T, Calogero A, Urcis R and Mercola D: Inhibition of Egr-1 expression reverses transformation of prostate cancer cells in vitro and in vivo. Oncogene 22: 4194-4204, 2003.

45. Zhang H, Chen X, Wang J, Guang W, Han W, Zhang H, Tan X and Gu Y: EGR1 decreases the malignancy of human non-small cell lung carcinoma by regulating KRT18 expression. Sci Rep 4: 5416, 2014 